\title{
Appendagitis in post-laparotomy hernia
}

\author{
A. D. Domínguez-Pérez, J. Aguilar-García, R. González-Martín, M. A. Iribarren-Marín, \\ B. Vargas-Serrano and P. Alcaide-León
}

Radiodiagnostic Unit. Hospitales Universitarios Virgen del Rocío. Sevilla, Spain

\section{CASE REPORT}

We present the case of a 46-year-old woman, with morbid obesity and a history of bariatric surgery with biliopancreatic derivation, and good postoperative evolution. One year after surgery, she presented symptoms of right upper quadrant pain of some hours duration, accompanied by fever and leukocytosis. We performed an abdominal CT with IV contrast which showed clinical indications of acute cholecystitis, although no signs of gallbladder inflammation were observed on ultrasound examination. Tomographic study -figure 1 in axial (A) and sagittal plane (B) - showed an ovoid lesion with the low attenuation characteristic of fat, banded by a hyperdense halo in relation to a postlaparotomy peritoneal defect (arrowheads). The lesion was in the proximity of the hepatic flexure (asterisk). These CT findings are consistent with a diagnosis of epiploic appendicitis within an omental fat collection herniated by a surgical defect (or postlaparotomy hernia).

\section{DISCUSSION}

The epiploic appendices are pedunculated fat formations, covered with serosa, which are found on the outer surface of the colon towards the peritoneal cavity (1). Omental appendicitis or apendagitis is the clinical expression of an ischemic infarction of an epiploic appendix (possibly caused by its twisting) or spontaneous thrombosis of the central vein that drains it. The clinical signs mimic many abdominal processes (appendicitis, cholecystitis, diverticulitis, ...) (2), but the treatment is very different in each case. A conservative approach is recommended, based on rest, analgesics and a light diet, without the need to use antibiotics or surgical treatment (3).

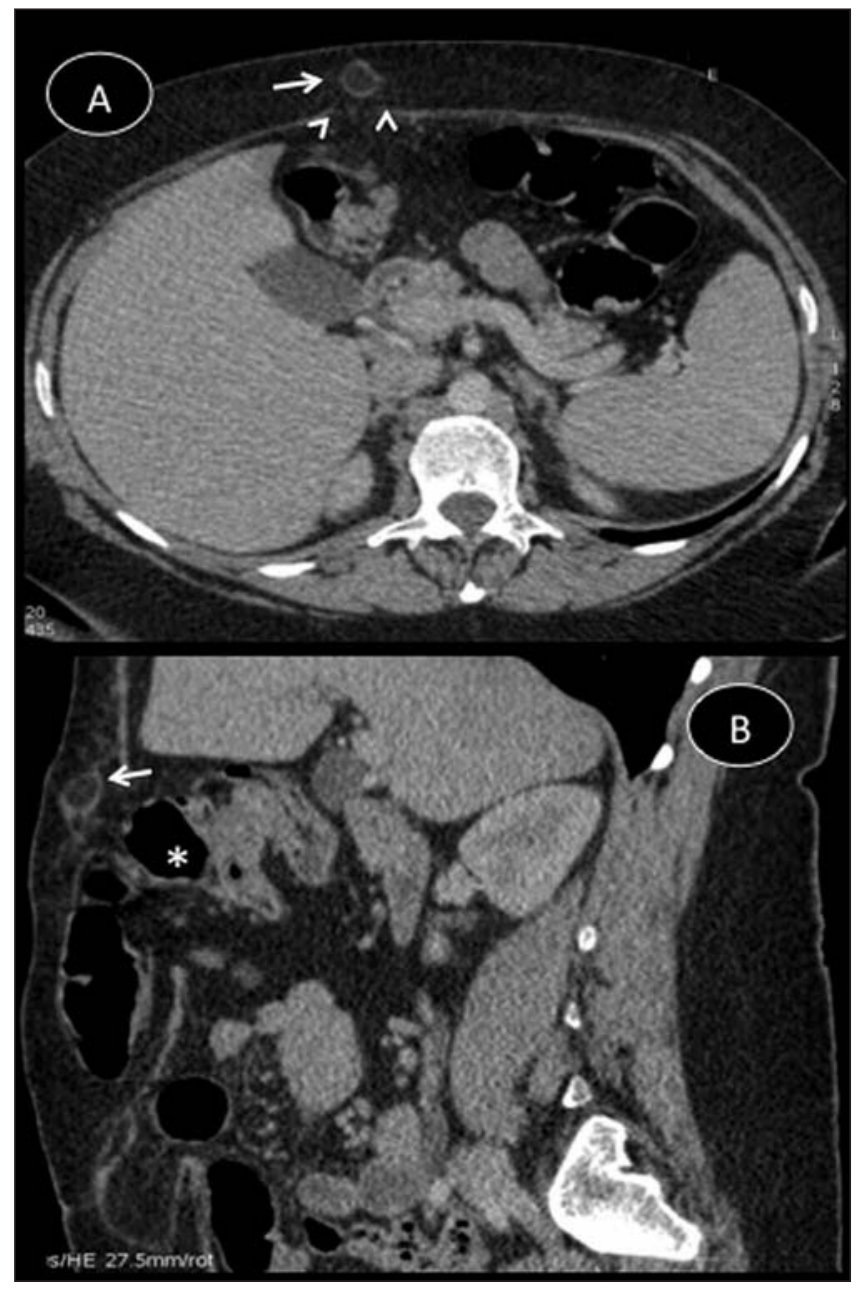

Fig. 1.

\section{REFERENCES}

1. Rodríguez Gandía MA, Moreira Vicente V, Gallego Rivera I, Rivero Fernández M, Garrido Gómez E. Epiploic appendicitis: the other apendicitis. Gastroenterol Hepatol 2008; 31(2): 98-103.

2. Sorser SA, Maas LC, Yousif E, Maas L. Epiploic appendagitis: the great mimicker. South Med J 2009; 102(12): 1214-7.

3. González Vega A, García Pérez I, Álvarez Álvarez D, Rizzo Ramos A, García Muñiz JL, Pérez Ricarte P. Epiploic appendagitis as a cause of acute abdominal pain. Rev Esp Enferm Dig 2008; 100(12): 800-1. 